\title{
Rapid simultaneous determination of 11 synthetic cannabinoids in urine by liquid chromatography-triple quadrupole mass spectrometry
}

Jianbing Wu ${ }^{1}$, Fang Zhang ${ }^{2}$, Xing Ke ${ }^{1}$, Wei Jia ${ }^{2}$, Xuzhi Wan ${ }^{2}$, Lange Zhang ${ }^{2}$, Laizhao Wang ${ }^{2}$, Yilei Fan ${ }^{1, *}$

${ }^{1}$ Key Laboratory of Drug Prevention and Control Technology of Zhejiang Province, Department of Criminal Science and Technology, Zhejiang Police College, Hangzhou, 310053, China

${ }^{2}$ Key Laboratory of Agro-Products Postharvest Handling of Ministry of Agriculture and Rural Affairs, Zhejiang Key Laboratory for Agro-Food Processing, College of Biosystems Engineering and Food Science, Zhejiang University, Hangzhou, 310058, Zhejiang, China

1, *Corresponding author at: Key Laboratory of Drug Prevention and Control Technology of Zhejiang Province, Department of Criminal Science and Technology, Zhejiang Police College, Hangzhou, 310053, China.

E-mail Address: fanyiei@zjjcxy.cn 


\begin{abstract}
:
Synthetic cannabinoids are a series of synthetic substances that mimic the effects of natural cannabinoids and produce a much stronger toxicity than natural cannabinoids, which have become the most abused family of new psychoactive substances. A solid-phase extractive-liquid chromatography-triple quadrupole/linear ion trap mass spectrometry method was developed to determine 11 synthetic cannabinoids in rat urine. The factors affecting recovery were optimized, and Oasis HLB was selected to extract synthetic cannabinoids simultaneously. The results showed that the linear correlation coefficients of the synthetic cannabinoids ranged from 0.993 to 0.999 , and the limit of quantitation ranged from 0.01 to $0.1 \mathrm{ng} / \mathrm{mL}$, and the spiked recoveries ranged from $69.90 \%$ to $118.39 \%$. This method has the advantages of good purification ability, simple operation, and good reproducibility, and can be used for the high sensitivity analysis of various synthetic cannabinoids in urine. Keywords: Synthetic cannabinoids; LC-MS/MS; Simultaneous determination; Matrix effect; Urine
\end{abstract}




\section{Introduction}

Cannabinoids can be divided into natural cannabinoids, endogenous cannabinoids, and synthetic cannabinoids based on the source. Synthetic cannabinoids (SCs) refer to the agonists of synthetic endogenous cannabinoid receptors (CB1 and $\mathrm{CB} 2$ ), which combine with cannabinoid receptors and have more potent physiological and pharmacological activities than natural cannabinoid [1]. SCs are mostly non-polar compounds with lipophilic properties composed of 22 to 26 carbon atoms[2]. SCs belong to psychoactive substances, including benzoyl indoles, benzoyl indoles, naphthyl indoles, cyclohexyl phenols, naphthyl pyrrole, and diamond indoles[3]. Aminoalkylindole JWH-018 is the first psychoactive ingredient identified from SCs product[4]. Synthetic cannabinoids develop from naphthoyl indole (JWH-018) to formylazole (THJ) to indazole (AKB-48) and then to indolecarbonamide (MDMBCHMINACA)[5].

Synthetic cannabinoids have many commercial names, such as Spice, Black Mamba, and Cold K2[6]. SCs have emerged in many countries and regions worldwide, especially among young people. SCs have been the most widely monitored new psychoactive substances in Europe since 2008[3]. The increase in consumption of SCs is particularly significant compared to other drugs on the market. Small changes in the original SCs structure will lead to the formation of new SCs, and thus many illegal manufacturers can easily produce new SCs. It is important to note that new SCs continue to emerge rapidly, making detection and analysis difficult.

Studies on the identification and toxicology of SCs have been carried out. Ingestion of cannabinoids can cause many diseases, as appeared and described in the literature, including psychosis[7], intoxication[8], tachycardia[9], changes in blood pressure[10], and atrial fibrillation[11]. Some reports declared a fatality directly related to the toxic effects of synthetic cannabinoid use[12,13]. Tomiyama et al. reported that SCs induce cell apoptosis by regulating the cascade of cystatin and stressed that the abuse of cannabinoids could lead to neurological brain problems [14]. Davide et al. concluded SCs could activate CB1 receptors in cardiomyocytes, participate in the production of reactive oxygen species, ATP consumption, and cell 
death, and then induce cardiotoxicity[15]. However, SCs also have been reported to have specific therapeutic effects. Aleksandra et al. found that SCs could activate the death pathway of human glioma cells and had anti-tumor activity[16]. Due to new SCs constantly emerging in the market, there is an urgent need to update the synchronous detection method of SCs. After being metabolized in the body, the content of the primary SCs is very low, and the matrix composition of biological samples is complex. Therefore, it is necessary to develop a low limit of quantitation and high precision method to detect trace synthetic cannabinoids in biological samples. Usually, blood and urine are the main biological samples tested for cannabinoids, while saliva and hair can also be used as critical biological samples for testing. The advantage of urine testing drugs is that the sample pretreatment process is simple, and the collection process of the urine sample is non-invasive. There are many types of SCs, and the structure of different types of synthetic cannabinoids varies greatly, which brings certain difficulties to the detection of synthetic cannabinoids. In recent years, the detection and analysis methods of synthetic cannabinoid drugs mainly include thin layer chromatography (TIC)[17], nuclear magnetic resonance (NMR)[18], infrared spectroscopy (IR)[19], gas chromatography-mass spectrometry (GC-MS)[20], liquid chromatography-mass spectrometry (LC-MS)[21], etc. Laith et al. developed GCMS to identify and quantify three common SCs seized on the market, including ABFUBINACA, AB-CHMINACA, and XLR-11, with LOD ranging from 0.15 to 17.89 $\mu \mathrm{g} / \mathrm{mL}[22]$. Dong et al. established LC-MS/MS for the identification and quantification of 3 major phytocannabinoids and their metabolites and four synthetic cannabinoids in human urine, with LOD ranging from 0.01 to $0.5 \mathrm{ng} / \mathrm{mL}$, and the extraction recovery rate exceeded $50 \%$, and the matrix effect was between $59.4 \%$ and $100.1 \%$ [23]. LCMS is mainly used to analyze compounds with high thermal instability, strong polarity, and high molecular weight, with the advantages of strong separation ability, low detection limit, high sensitivity, and high accuracy[23]. Therefore, LC-MS is widely used to analyze multiple SCs in biopages simultaneously.

This article presented an improved and fully validated LC-MS/MS method for detecting 11 synthetic cannabinoids in rat urine. The method validation process 
involves the assessment of linearity, precision, accuracy, and limits of quantification. In addition, SCs concentrations in urine were measured at different time points after injection of synthetic cannabinoids in rats. This method provides a useful tool for the identification of SCs in rat urines and a reference for the assessment of SCs internal biological exposure.

\section{Materials and methods}

\subsection{Chemicals and Reagents}

Synthetic cannabinoid standard: N-(1-Amino-3-methyl-1-oxobutan-2-yl)-1- pentyl-1H-indazole-3-carboxamide (AB-PINACA), (1-Pentyl-1H-indol-3-yl)(4methylnaphthalen-1-yl)methanone (JWH-122), N-(1-Amino-3-methyl-1-oxobutan-2yl)-1-(cyclohexylmethyl)-1H-indazole-3-carboxamide (AB-CHMINACA), 1-Pentyl-3-(4methoxybenzoyl)indole (RCS-4), N-(1-Methoxy-3,3-dimethyl-1-oxobutan-2-yl)-1-(4fluorobenzyl)-1H-indazole-3-carboxamide (MDMB-FUBINACA), N-[1-(amino-3,3dimethyl-1-oxobutan-2-yl)-1-(4-fluorobenzyl)-1H-indazole-3-carboxamide

(ADBFUBINACA), methyl 2-[1-(5-fluoropentyl)-1H-indazole-3-carboxamido]-3,3dimethylbutanoate (5F-ADB), Methyl-2-[[1-(5-fluoropentyl)indole-3-carbonyl]amino]3,3-dimethyl-butanoate) (5F-MDMB-PICA), N-[[1-(5-Fluoropentyl)-1H-indazol-3yl]carbonyl]valine methyl ester (5F-AMB), (1-Pentyl-1H-indol-3-yl)(2,2,3,3tetramethylcyclopropyl)methanone (UR-144) and methyl (S)-2-[1-(4-fluorobenzyl)-1Hindazole-3-carboxamido]-3-methylbutanoate (AMB-FUBINACA) were obtained from Shanghai Institute of Criminal Science and Technology. Formic acid ( $\geq 96 \%$, HPLC grade) was purchased from ROE scientific INC. (Barksdale Professional Center, Newark, USA); methanol and acetonitrile (HPLC-grade both) were obtained from Merck (New Jersey, USA). Ultrapure water (Millipore, Bedford, USA) was used throughout the whole study.

\subsection{Animal study}

Blank urine of male rats were obtained from Zhejiang Academy of Medical Sciences (Zhejiang, China). The Sprague-Dawley male rats $(n=12$, six weeks, weighing 190$210 \mathrm{~g}$ ) were obtained from Zhejiang Academy of Medical Sciences (Zhejiang, China) 
and acclimatized for one week before collection of urine in the experimental room (temperature $23 \pm 2{ }^{\circ} \mathrm{C}$, humidity $55 \pm 10 \%, 12 \mathrm{~h}$ light-dark cycle). After 1-week adaptation, all the rats were transferred to an individually metabolic cage to collect the urine samples and stored at $-20^{\circ} \mathrm{C}$ for further study. All experimental procedures were approved by the Zhejiang Experimental Animal Center. Experimental Animal Welfare and Ethical Review Committee (Approval ID: ZJCLA-IACUC-20100005; Hangzhou, China).

\subsection{Working Standards and Calibration Standards}

Stock standard solutions of 11 synthetic cannabinoids were prepared by dissolving $1 \mathrm{mg}$ of analytes in $1 \mathrm{~mL}$ of methanol to obtain the concentration of $1 \mathrm{mg} / \mathrm{mL}$ and were kept at $-20^{\circ} \mathrm{C}$. Mixed stock standard solutions were prepared by diluting the stock standard solutions of 11 synthetic cannabinoids with acetonitrile to obtain the concentration of $10 \mu \mathrm{g} / \mathrm{mL}$. Mixed working standard solutions were prepared by diluting mixed stock standard solutions with acetonitrile to obtain a series of concentrations according to the experiment's needs.

\subsection{Pretreatment of Urine Samples}

The synthetic cannabinoids of the urine sample were extracted by Oasis HLB cartridge (3cc $60 \mathrm{mg}$, Waters, St. Quentin en Yvelines, France). $400 \mu \mathrm{L}$ of urine sample was mixed with $600 \mu \mathrm{L}$ of acetonitrile and $1 \mathrm{~mL}$ of ultrapure water and vortexed for 30 s. The SPE cartridge was pre-conditioned with $3 \mathrm{~mL}$ of methanol and then equilibrated with $6 \mathrm{~mL}$ of ultrapure water before loading the mixed solution onto the cartridge. After loading, $3 \mathrm{~mL}$ of methanol water $(5 \%, v / \mathrm{v})$ was added for washing, and $4 \mathrm{~mL}$ of methanol was added for elution. The eluant was dried under a nitrogen stream and then reconstituted with $200 \mu \mathrm{L}$ of acetonitrile for analysis by LC-MS/MS.

\subsection{Determination of Synthetic Cannabinoids by LC-MS/MS}

The AB SCIEX ExionLCTMOAD XR high-performance liquid chromatography system coupled with AB SCIEX QTRAP 6500+ triple quadrupole/linear ion trap mass spectrometer system (AB SCIEX, Framingham, MA, USA) was used for analysis. The analytes were separated on a Waters UPLC HSS T3 column $(1.8 \mu \mathrm{m}, 2.1 \mathrm{~mm} \times 150$ 
$\mathrm{mm}$ ) with the column temperature set at $40^{\circ} \mathrm{C}$. The binary solvent system consisted of $0.1 \%(\mathrm{v} / \mathrm{v})$ aqueous formic acid solution $(\mathrm{A})$ and acetonitrile $(\mathrm{B})$. The gradient profile of the binary pump maintained at $90 \% \mathrm{~A}$ from 0 to $1.0 \mathrm{~min}$, decreased to $0 \% \mathrm{~A}$ from 1.0 to $7.0 \mathrm{~min}$, maintained at $0 \% \mathrm{~A}$ from 7.0 to $11.0 \mathrm{~min}$, then went back to $90 \% \mathrm{~A}$ at $11.1 \mathrm{~min}$, and finally held for $5 \mathrm{~min}$. The flow rate was $0.3 \mathrm{~mL} / \mathrm{min}$. The equipment was operated in electrospray positive ionization mode $(\mathrm{ESI}+)$ under the multiple reaction monitoring mode (MRM). Optimized source parameters were set as follows: curtain gas $35 \mathrm{Psi}$, collision gas medium, ionspray voltage $5500 \mathrm{~V}(\mathrm{ESI})$, temperature $550^{\circ} \mathrm{C}$, ion source gas1 $50 \mathrm{Psi}$, ion source gas2 $50 \mathrm{Psi}$. The optimized mass spectra data of 11 SCs are shown in Table 1, and the chromatographic mass spectra of the standard solution $(10 \mathrm{ng} / \mathrm{mL})$ are shown in Figure1.

\subsection{Method Validation}

The method's calibration curves, linear ranges, matrix effect, recovery, precision, and limit of quantification (LOQ) were determined according to Taverniers et al. for a robust method validation[24]. In simple terms, 11 synthetic cannabinoid standard compounds were added to pretreated blank rat urine to configure standard matrix curves. Blank rat urine samples were treated with solid-phase extraction method, and then mixed standard substances of 11 SCs were added to prepare $0.1 \mathrm{ng} / \mathrm{mL}$, one $\mathrm{ng} / \mathrm{mL}$, and ten $\mathrm{ng} / \mathrm{mL}$ spiked rat urine sample solution to calculate matrix effect. We used intraday relative standard deviation to verify the precision of LC-MS/MS detection of SCs. The samples were injected six times at different times in a day, the average was taken, and the test results $(n=6)$ were analyzed. The recovery rate of this method examined the entire urine sample pretreatment step and was determined by the standard addition method. Recovery tests were performed by adding low, medium, and high levels of 11 standard solutions of cannabinoids to a blank matrix. The signalto-noise ratio $(S / N)$ of the blank matrix diluted to HPLC MS/MS system was 10 , and the limits of quantification were determined.

\section{Results and discussion}

\subsection{Optimization of sample pretreatment}


For the pretreatment of urine matrix, liquid-liquid extraction or solid-phase extraction methods are usually adopted. As a conventional extraction method, liquidliquid extraction has the disadvantages of large consumption of organic solvents and unstable recovery[25]. Compared with liquid-liquid extraction, solid-phase extraction has advantages of high enrichment ratio, high accuracy, and clean matrix treatment, so it is widely used[26]. Yeter et al. used liquid chromatography-high-resolution mass spectrometry to determine the 5F-ADB and its methyl ester metabolite in blood and urine samples. Urine and blood samples are pretreated with solid-phase extraction cartridge (OASIS HLB, $3 \mathrm{cc}, 60 \mathrm{mg}$ ). The method was successfully applied to 70 human blood and 36 urine samples[27]. Our laboratory has investigated three types of solid-phase extraction columns, Waters Oasis HLB, Waters Oasis WCX, and Waters Oasis MCX. Preliminary experimental results showed that SCs could not be retained on weak cation-exchange mixed columns and strong cation-exchange mixed columns. Therefore, Waters Oasis WCX and Waters Oasis MCX are not suitable for the pretreatment of synthetic cannabinoids. Waters Oasis HLB column is a hydrophilic and lipophilic balanced reverse phase adsorbent ideal for all substrates and capable of removing $95 \%$ of common substrate interferers such as phospholipid, fatty salts, and proteins[28]. And the adsorbent does not require adjustment and balancing steps, and the recovery rate is high. Per Ole M. Gundersen compared different solid-phase extraction columns to quantify the SCs metabolites in the urine by UHPLC-QTOF-MS, and finally selected HLB solid-phase extraction columns[29]. Based on the physical and chemical properties of 11 synthetic cannabinoids, the Waters Oasis HLB column was selected as a solid-phase extraction column for pretreatment optimization.

We also investigated the effects of the acetonitrile ratio of loading solution on the extraction recovery of 11 SCs. Since most SCs are lipophilic and insoluble in water, the use of ultrapure water as the loading liquid will result in the incomplete transfer of SCs to the SPE column. We added a certain volume of acetonitrile to the sample solution to make the SCs dissolve better in the loading solution. However, a large proportion of acetonitrile in the loading solution could lead to elution of the tested substance during loading. Therefore, it is essential to select the appropriate loading 
solution. We kept the volume of the measured substance and rat urine constant, and changed the volume of acetonitrile and ultrapure water. We set the volume of acetonitrile as $400 \mu \mathrm{L}, 600 \mu \mathrm{L}$, and $800 \mu \mathrm{L}$ and added a certain volume of ultrapure water, respectively, so that the total volume of the final sample solution was $2 \mathrm{~mL}$. The results showed that the proportion of acetonitrile in the loading solution significantly affected the extraction recovery of 11 SCs (Figure 2). When the volumes of acetonitrile were 400,600 , and $800 \mu \mathrm{L}$, respectively, the extraction recovery rates were 52.7$122.3 \%, 85.3-119.5 \%$, and $85.1-106.4 \%$. The final acetonitrile volume was determined to be $600 \mu \mathrm{L}$ (Figure 2). Akamatsu et al. also optimized the volume of acetonitrile to improve the separation effect of micellar electrokinetic chromatography-triple quadrupole mass spectrometry (MEKC-MS/MS) for the simultaneous determination of SCs and concluded that $20 \%$ V/V acetonitrile could produce better peak resolution[30].

We also investigated the effect of elution reagent volume on the extraction recovery of 11 SCs. To completely elute 11 SCs while reducing the amount of organic reagent, the volume of elution reagent was set as $2 \mathrm{~mL}, 3 \mathrm{~mL}, 4 \mathrm{~mL}, 5 \mathrm{~mL}$, and $6 \mathrm{~mL}$. Results showed that the volume of elution reagent greatly influenced the extraction recovery of SCs (Figure 3). Theoretically, as the elution reagent mentioned increased, the recovery rate would gradually increase. The results showed that when the volumes of elution reagents were $2 \mathrm{~mL}, 3 \mathrm{~mL}, 4 \mathrm{~mL}, 5 \mathrm{~mL}$, and $6 \mathrm{~mL}$, respectively, the recovery rates of 11 SCs were $15.5-20.2 \%, 50.4-79.5 \%, 79.6-104 \%, 81.4-103.1 \%$, and $82.7-$ $107.9 \%$, respectively. It could be seen that when the recovery rate varied little when the elution reagent volume was $4 \mathrm{~mL}, 5 \mathrm{~mL}$, and $6 \mathrm{~mL}$. When the volume of the elution reagent was $4 \mathrm{~mL}$, all the 11 SCs could achieve a good extraction recovery (Figure 3). Different from our results, Borova et al. studied SPE conditions to detect ten new psychoactive substances and found that adding $4 \mathrm{~mL}$ methanol and following $8 \mathrm{~mL}$ of

a mixture of $\mathrm{MeOH} / \mathrm{EtAc}$ 1:1 had a better effect during the elution of SPE with a VARIAN (Vac Elut SPS 24) manifold and PolyClean 2H (200 mg) cartridges[31].

\subsection{Establishment of standard curves}

After pretreatment, 11 SCs standard compounds were added into blank rat urine to configure matrix standard curves and the concentrations of the 11 standard curves 
were $0.05 \mathrm{ng} / \mathrm{mL}, 0.1 \mathrm{ng} / \mathrm{mL}, 0.2 \mathrm{ng} / \mathrm{mL}, 0.5 \mathrm{ng} / \mathrm{mL}, 1 \mathrm{ng} / \mathrm{mL}, 5 \mathrm{ng} / \mathrm{mL}, 10 \mathrm{ng} / \mathrm{mL}$ and $20 \mathrm{ng} / \mathrm{mL}$. The matrix standard curve and the prepared samples were analyzed by LCMS/MS. Linear regression is performed with the peak area as the ordinate coordinate and the standard solution concentration as the abscissa. The linear regression equation was obtained with a linear range of $0.05-10 \mathrm{ng} / \mathrm{mL}$ (Table 2). The results show that all 11 target analytes are linear in the range of $0.05-10 \mathrm{ng} / \mathrm{mL}$, and the correlation coefficient is between 0.993-0.999. The linear fit complex correlation coefficient in the linear regression equation is greater than 0.99 , indicating good linearity[32].

\subsection{Method validation}

Blank rat urine samples were treated with solid-phase extraction method, and then mixed standard substances of 11 SCs were added to prepare $0.1 \mathrm{ng} / \mathrm{mL}$, one $\mathrm{ng} / \mathrm{mL}$, and ten $\mathrm{ng} / \mathrm{mL}$ spiked rat urine sample solution. When diluting urine with acetonitrile reagent, other substances along with the analyte, including salts, amines, fatty acids, and other small molecules. The flow of these substances and analytes out of the spray needle can affect the atomization, volatilization, splitting, chemical reaction, and charging process of the analyte, resulting in a decrease or increase in ions entering the mass spectrometry, thereby affecting the reliability and accuracy of quantitative results. The final matrix effect range in our experiment was $76.7 \%-106.1 \%$ (Table 3). In addition to AB-PINACA, the matrix effects of the 11 SCs are all within 80$100 \%$, indicating that the influence of the matrix is small[33]. It can be concluded that the optimized solid-phase extraction method can effectively reduce the matrix effect.

The blank rat urine was mixed with 11 kinds of SCs, and the concentrations were one $\mathrm{ng} / \mathrm{mL}$, ten $\mathrm{ng} / \mathrm{mL}$, and $100 \mathrm{ng} / \mathrm{mL}$, respectively. Urine samples from rats $(\mathrm{n}=6)$ were treated with SPE to evaluate the recovery and precision of target analytes extracted by SPE pretreatment. The spiked recoveries of 11 SCs at three levels were $69.90-118.39 \%$ (Table 4). As for the accuracy in method verification, the generally acceptable recovery rate ranges from 80 to $120 \%$, indicating that the recovery rate of this method is within the acceptable range[34]. And the intraday precision was $0.52-$ $18.95 \%$. The systematic and random errors of the illustrative method are minor so that 
they can meet the quantitative analysis. The LOQ was the concentration of the analyte when the signal-noise ratio was 10 . LOQ were $0.01 \mathrm{ng} / \mathrm{mL}$ for $\mathrm{JWH}-122$ and AMBFUBINACA, $0.03 \mathrm{ng} / \mathrm{mL}$ for 5F-AMB, UR-144, RCS-4 and 5F-ADB, and $0.1 \mathrm{ng} / \mathrm{mL}$ for AB-CHMINACA, AB-PINACA, ADB-FUBINACA, MDMB-FUBINACA and 5F-MDMBPICA (Table 2). This method meets the requirements of trace detection. LOQ is lower than most previous studies that detect SCs in urine[26,35,36].

\section{Conclusion}

In our study, the solid-phase extraction LC-MS/MS method was established to determine 11 synthetic cannabinoids in rat urine. By optimizing SPE conditions, the Waters Oasis HLB column had an excellent barrier effect on impurities in biological samples. The acetonitrile ratio and the elution reagent volume were optimized to improve the recovery rate of tested samples. The results showed that the method had high sensitivity and good reproducibility, and the LOQ was $0.01-0.1 \mathrm{ng} / \mathrm{mL}$ less than reported in the vast majority of literature. The spiked recoveries of 11 SCs were 69.90$118.39 \%$, and the intraday precision was $0.52-18.95 \%$. This method has been successfully applied to the analysis of cannabinoids in urine samples of rats. This method could detect synthetic cannabinoids in urine quickly, accurately and effectively, which is of great significance for the rapid detection of drug-related cases and the strict prevention of drug-related criminal activities.

\section{Acknowledgments}

This work was supported by the Science and Technology Department of Zhejiang Province (No. LGC21B050001) and the Open Project Program of Key Laboratory of Drug Prevention and Control Technology of Zhejiang Province (No. 2020010), and the Scientific Research Project of Zhejiang Police College (No. 2018QNY022).

\section{Declaration of Competing Interest}

The authors declare no competing financial interest. 


\section{Reference}

1. Alipour, A.; Patel, P.B.; Shabbir, Z.; Gabrielson, S. Review of the many faces of synthetic cannabinoid toxicities. Ment Health Clin 2019, 9, 93-99, doi:10.9740/mhc.2019.03.093.

2. Alves, V.L.; Goncalves, J.L.; Aguiar, J.; Teixeira, H.M.; Camara, J.S. The synthetic cannabinoids phenomenon: from structure to toxicological properties. A review. Crit Rev Toxicol 2020, 50, 359382, doi:10.1080/10408444.2020.1762539.

3. Pintori, N.; Loi, B.; Mereu, M. Synthetic cannabinoids: the hidden side of Spice drugs. Behav Pharmacol 2017, 28, 409-419, doi:10.1097/FBP.0000000000000323.

4. Simolka, K.; Lindigkeit, R.; Schiebel, H.M.; Papke, U.; Ernst, L.; Beuerle, T. Analysis of synthetic cannabinoids in "spice-like" herbal highs: snapshot of the German market in summer 2011. Anal Bioanal Chem 2012, 404, 157-171, doi:10.1007/s00216-012-6122-4.

5. Zanda, M.T.; Fattore, L. Old and new synthetic cannabinoids: lessons from animal models. Drug Metab Rev 2018, 50, 54-64, doi:10.1080/03602532.2018.1430824.

6. Karila, L.; Benyamina, A.; Blecha, L.; Cottencin, O.; Billieux, J. The Synthetic Cannabinoids Phenomenon. Current Pharmaceutical Design 2016, 22, 6420-6425, doi:http://dx.doi.org/10.2174/1381612822666160919093450.

7. Deng, H.; Verrico, C.D.; Kosten, T.R.; Nielsen, D.A. Psychosis and synthetic cannabinoids. Psychiatry Res 2018, 268, 400-412, doi:10.1016/j.psychres.2018.08.012.

8. Adamowicz, P.; Meissner, E.; Maslanka, M. Fatal intoxication with new synthetic cannabinoids AMB-FUBINACA and EMB-FUBINACA. Clin Toxicol (Phila) 2019, 57, 1103-1108, doi:10.1080/15563650.2019.1580371.

9. Dobaja, M.; Grenc, D.; Kozelj, G.; Brvar, M. Occupational transdermal poisoning with synthetic cannabinoid cumyl-PINACA. Clin Toxicol (Phila) 2017, 55, 193-195, doi:10.1080/15563650.2016.1278224.

10. Malinowska, B.; Baranowska-Kuczko, M.; Schlicker, E. Triphasic blood pressure responses to cannabinoids: do we understand the mechanism? $\mathrm{Br} J$ Pharmacol 2012, 165, 2073-2088, doi:10.1111/j.1476-5381.2011.01747.x.

11. Anzillotti, L.; Marezza, F.; Calo, L.; Banchini, A.; Cecchi, R. A case report positive for synthetic cannabinoids: are cardiovascular effects related to their protracted use? Leg Med (Tokyo) 2019, 41, 101637, doi:10.1016/j.legalmed.2019.101637.

12. Angerer, V.; Jacobi, S.; Franz, F.; Auwarter, V.; Pietsch, J. Three fatalities associated with the synthetic cannabinoids 5F-ADB, 5F-PB-22, and AB-CHMINACA. Forensic Sci Int 2017, 281, e9e15, doi:10.1016/j.forsciint.2017.10.042.

13. Boland, D.M.; Reidy, L.J.; Seither, J.M.; Radtke, J.M.; Lew, E.O. Forty-Three Fatalities Involving the Synthetic Cannabinoid, 5-Fluoro-ADB: Forensic Pathology and Toxicology Implications. J Forensic Sci 2020, 65, 170-182, doi:10.1111/1556-4029.14098.

14. Tomiyama, K.; Funada, M. Cytotoxicity of synthetic cannabinoids on primary neuronal cells of the forebrain: the involvement of cannabinoid CB1 receptors and apoptotic cell death. Toxicol Appl Pharmacol 2014, 274, 17-23, doi:10.1016/j.taap.2013.10.028.

15. Radaelli, D.; Manfredi, A.; Zanon, M.; Fattorini, P.; Scopetti, M.; Neri, M.; Frisoni, P.; D'Errico, S. Synthetic Cannabinoids and Cathinones Cardiotoxicity: Facts and Perspectives. Curr Neuropharmacol 2021, 19, 2038-2048, doi:10.2174/1570159X19666210412101929.

16. Ellert-Miklaszewska, A.; Ciechomska, I.A.; Kaminska, B. Synthetic Cannabinoids Induce Autophagy and Mitochondrial Apoptotic Pathways in Human Glioblastoma Cells Independently of 
Deficiency in TP53 or PTEN Tumor Suppressors. Cancers (Basel) 2021, 13, doi:10.3390/cancers13030419.

17. Sherma, J.; Rabel, F. Thin layer chromatography in the analysis of cannabis and its components and synthetic cannabinoids. Journal of Liquid Chromatography \& Related Technologies 2019, 42, 613-628, doi:10.1080/10826076.2019.1663529.

18. Dybowski, M.P.; Holowinski, P.; Typek, R.; Dawidowicz, A.L. Comprehensive analytical characteristics of $\mathrm{N}$-(adamantan-1-yl)-1- (cyclohexylmethyl)-1H-indazole-3-carboxamide (ACHMINACA). Forensic Toxicology 2020, 39, 230-239, doi:10.1007/s11419-020-00547-6.

19. Lee, J.H.; Jung, A.; Park, H.N.; Lee, C.; Mandava, S.; Lim, S.J.; Lim, B.B.; Park, S.K.; Lee, J.; Kang, $\mathrm{H}$. Identification and characterization of an indazole-3-carboxamide class synthetic cannabinoid: 2[1-(cyclohexylmethyl)-1H-indazole-3-carboxamido]-3,3-dimethylbutanoic acid (DMBACHMINACA). Forensic Sci Int 2018, 291, 167-174, doi:10.1016/j.forsciint.2018.08.028.

20. Anzillotti, L.; Marezza, F.; Calo, L.; Andreoli, R.; Agazzi, S.; Bianchi, F.; Careri, M.; Cecchi, R. Determination of synthetic and natural cannabinoids in oral fluid by solid-phase microextraction coupled to gas chromatography/mass spectrometry: A pilot study. Talanta 2019, 201, 335-341, doi:10.1016/j.talanta.2019.04.029.

21. Staeheli, S.N.; Veloso, V.P.; Bovens, M.; Bissig, C.; Kraemer, T.; Poetzsch, M. Liquid chromatography-tandem mass spectrometry screening method using information-dependent acquisition of enhanced product ion mass spectra for synthetic cannabinoids including metabolites in urine. Drug Test Anal 2019, 11, 1369-1376, doi:10.1002/dta.2664.

22. Al-Eitan, L.N.; Asa'ad, A.S.; Battah, A.H.; Aljamal, H.A. Application of Gas Chromatography-Mass Spectrometry for the Identification and Quantitation of Three Common Synthetic Cannabinoids in Seized Materials from the Jordanian Market. ACS Omega 2020, 5, 4172-4180, doi:10.1021/acsomega.9b03881.

23. Dong, X.; Li, L.; Ye, Y.; Zheng, L.; Jiang, Y. Simultaneous determination of major phytocannabinoids, their main metabolites, and common synthetic cannabinoids in urine samples by LC-MS/MS. $J$ Chromatogr B Analyt Technol Biomed Life Sci 2016, 1033-1034, 55-64, doi:10.1016/j.jchromb.2016.08.002.

24. Taverniers, I.; De Loose, M.; Van Bockstaele, E. Trends in quality in the analytical laboratory. II. Analytical method validation and quality assurance. TrAC Trends in Analytical Chemistry 2004, 23 , 535-552, doi:10.1016/j.trac.2004.04.001.

25. Ambroziak, K.; Adamowicz, P. Simple screening procedure for 72 synthetic cannabinoids in whole blood by liquid chromatography-tandem mass spectrometry. Forensic Toxicol 2018, 36, 280-290, doi:10.1007/s11419-017-0401-x.

26. Simoes, S.S.; Silva, I.; Ajenjo, A.C.; Dias, M.J. Validation and application of an UPLC-MS/MS method for the quantification of synthetic cannabinoids in urine samples and analysis of seized materials from the Portuguese market. Forensic Sci Int 2014, 243, 117-125, doi:10.1016/j.forsciint.2014.07.022.

27. Yeter, O.; Erol Ozturk, Y. Detection and quantification of 5F-ADB and its methyl ester hydrolysis metabolite in fatal intoxication cases by liquid chromatography-high resolution mass spectrometry. Forensic Sci Int 2019, 302, 109866, doi:10.1016/j.forsciint.2019.06.024.

28. Herrero, P.; Borrull, F.; Pocurull, E.; Marce, R.M. Novel amide polar-embedded reversed-phase column for the fast liquid chromatography-tandem mass spectrometry method to determine polyether ionophores in environmental waters. J Chromatogr A 2012, 1263, 7-13, 
doi:10.1016/j.chroma.2012.09.017.

29. Gundersen, P.O.M.; Spigset, O.; Josefsson, M. Screening, quantification, and confirmation of synthetic cannabinoid metabolites in urine by UHPLC-QTOF-MS. Drug Test Anal 2019, 11, 51-67, doi:10.1002/dta.2464.

30. Akamatsu, S.; Mitsuhashi, T. MEKC-MS/MS method using a volatile surfactant for the simultaneous determination of 12 synthetic cannabinoids. J Sep Sci 2014, 37, 304-307, doi:10.1002/jssc.201301132.

31. Borova, V.L.; Gago-Ferrero, P.; Pistos, C.; Thomaidis, N.S. Multi-residue determination of 10 selected new psychoactive substances in wastewater samples by liquid chromatography-tandem mass spectrometry. Talanta 2015, 144, 592-603, doi:10.1016/j.talanta.2015.06.080.

32. Yuan, L.; Zhang, D.; Jemal, M.; Aubry, A.F. Systematic evaluation of the root cause of non-linearity in liquid chromatography/tandem mass spectrometry bioanalytical assays and strategy to predict and extend the linear standard curve range. Rapid Commun Mass Spectrom 2012, 26, 1465-1474, doi:10.1002/rcm.6252.

33. Ucles, S.; Lozano, A.; Sosa, A.; Parrilla Vazquez, P.; Valverde, A.; Fernandez-Alba, A.R. Matrix interference evaluation employing GC and LC coupled to triple quadrupole tandem mass spectrometry. Talanta 2017, 174, 72-81, doi:10.1016/j.talanta.2017.05.068.

34. Díaz, A.; Vàzquez, L.s.; Ventura, F.; Galceran, M.T. Estimation of measurement uncertainty for the determination of nonylphenol in water using solid-phase extraction and solid-phase microextraction procedures. Analytica Chimica Acta 2004, 506, 71-80, doi:10.1016/j.aca.2003.10.083.

35. Knittel, J.L.; Holler, J.M.; Chmiel, J.D.; Vorce, S.P.; Magluilo, J., Jr.; Levine, B.; Ramos, G.; Bosy, T.Z. Analysis of Parent Synthetic Cannabinoids in Blood and Urinary Metabolites by Liquid Chromatography Tandem Mass Spectrometry. J Anal Toxicol 2016, 40, 173-186, doi:10.1093/jat/bkv137.

36. Borg, D.; Tverdovsky, A.; Stripp, R. A Fast and Comprehensive Analysis of 32 Synthetic Cannabinoids Using Agilent Triple Quadrupole LC-MS-MS. J Anal Toxicol 2017, 41, 6-16, doi:10.1093/jat/bkw104. 


\begin{tabular}{cccccc}
\hline Compound & $\begin{array}{c}\text { Molecular } \\
\text { formula }\end{array}$ & $\begin{array}{c}\text { Retention } \\
\text { time } \\
(\mathrm{min})\end{array}$ & $\begin{array}{c}\text { Precursor } \\
\text { ion }(\mathrm{m} / \mathrm{z})\end{array}$ & $\begin{array}{c}\text { Daughter ion } \\
(\mathrm{m} / \mathrm{z})\end{array}$ & $\begin{array}{c}\text { Collision } \\
\text { energy } \\
(\mathrm{V})\end{array}$ \\
\hline JWH-122 & $\mathrm{C}_{25} \mathrm{H}_{25} \mathrm{NO}$ & 8.98 & 356.2 & $169.2^{\mathrm{a} / 214.2}$ & $32 / 32$ \\
5F-AMB & $\mathrm{C}_{19} \mathrm{H}_{26} \mathrm{FN}_{3} \mathrm{O}_{3}$ & 7.60 & 364.2 & $233.2^{\mathrm{a} / 304.2}$ & $32 / 21$ \\
AMB-FUBINACA & $\mathrm{C}_{21} \mathrm{H}_{21} \mathrm{FN}_{3} \mathrm{O}_{3}$ & 7.73 & 384.2 & $253.2^{\mathrm{a}} / 324.2$ & $30 / 23$ \\
UR-144 & $\mathrm{C}_{21} \mathrm{H}_{29} \mathrm{NO}$ & 9.21 & 312.2 & $125.2^{2} / 214.1$ & $30 / 32$ \\
RCS-4 & $\mathrm{C}_{21} \mathrm{H}_{23} \mathrm{NO}_{2}$ & 8.21 & 322.2 & $135.2^{\mathrm{a} / 214.2}$ & $31 / 32$ \\
AB-CHMINACA & $\mathrm{C}_{20} \mathrm{H}_{28} \mathrm{~N}_{4} \mathrm{O}_{2}$ & 7.34 & 357.2 & $241.2^{\mathrm{a} / 169.2}$ & $34 / 35$ \\
AB-PINACA & $\mathrm{C}_{18} \mathrm{H}_{26} \mathrm{~N}_{4} \mathrm{O}_{2}$ & 6.95 & 331.2 & $286.2^{2} / 314.2$ & $21 / 13$ \\
MDMB-FUBINACA & $\mathrm{C}_{22} \mathrm{H}_{24} \mathrm{FN}_{3} \mathrm{O}_{3}$ & 8.02 & 398.2 & $253.1^{\mathrm{a} / 338.1}$ & $33 / 19$ \\
5F-ADB & $\mathrm{C}_{20} \mathrm{H}_{28} \mathrm{FN}_{3} \mathrm{O}_{3}$ & 7.91 & 378.2 & $223.1^{\mathrm{a} / 318.3}$ & $31 / 23$ \\
ADB-FUBINACA & $\mathrm{C}_{21} \mathrm{H}_{23} \mathrm{FNN}_{4} \mathrm{O}_{2}$ & 6.82 & 383.1 & $253.1^{\mathrm{a} / 338.2}$ & $34 / 23$ \\
5F-MDMB-PICA & $\mathrm{C}_{21} \mathrm{H}_{29} \mathrm{FNN}_{2} \mathrm{O}_{3}$ & 7.53 & 377.2 & $144.1^{\mathrm{a} / 232.2}$ & $56 / 20$ \\
\hline
\end{tabular}

Table 1 Synthetic cannabinoids chromatography-mass spectrometry parameters.

a Quantifier ions

\begin{tabular}{cccc}
\hline Compound & Urine matrix standard curve & $\mathrm{R}^{2}$ & $\begin{array}{c}\mathrm{LOQ} \\
(\mathrm{ng} / \mathrm{mL})\end{array}$ \\
\hline JWH-122 & $\mathrm{y}=3.02938 \mathrm{e} 6 \mathrm{x}+5.09168 \mathrm{e} 4$ & 0.99841 & 0.01 \\
5F-AMB & $\mathrm{y}=2.88293 \mathrm{e} 6 \mathrm{x}+5.16729 \mathrm{e} 4$ & 0.99835 & 0.03 \\
AMB-FUBINACA & $\mathrm{y}=2.86395 \mathrm{e} 6 \mathrm{x}+4.24124 \mathrm{e} 4$ & 0.99930 & 0.01 \\
UR-144 & $\mathrm{y}=1.48598 \mathrm{e} 6 \mathrm{x}+27734.81100$ & 0.99912 & 0.03 \\
RCS-4 & $\mathrm{y}=3.80986 \mathrm{e} 6 \mathrm{x}+1.12702 \mathrm{e} 5$ & 0.99578 & 0.03 \\
AB-CHMINACA & $\mathrm{y}=3.45358 \mathrm{e} 5 \mathrm{x}+5.58886 \mathrm{e} 4$ & 0.99829 & 0.1 \\
AB-PINACA & $\mathrm{y}=3.47936 \mathrm{e} 5 \mathrm{x}+20569.85965$ & 0.99894 & 0.1 \\
MDMB-FUBINACA & $\mathrm{y}=1.44915 \mathrm{e} 6 \mathrm{x}+5.04729 \mathrm{e} 4$ & 0.99726 & 0.03 \\
5F-ADB & $\mathrm{y}=9.51164 \mathrm{e} 5 \mathrm{x}+6.20371 \mathrm{e} 4$ & 0.99592 & 0.03 \\
ADB-FUBINACA & $\mathrm{y}=2.35373 \mathrm{e} 6 \mathrm{x}+6.78715 \mathrm{e} 4$ & 0.99253 & 0.1 \\
5F-MDMB-PICA & $\mathrm{y}=9.01193 \mathrm{e} 5 \mathrm{x}+8.52260 \mathrm{e} 4$ & 0.99541 & 0.1 \\
\hline
\end{tabular}

Table 2 Synthetic cannabinoid urine matrix standard curve equation and limits of quantification. 


\begin{tabular}{cccc}
\hline Compound & $\begin{array}{c}0.1 \mathrm{ng} / \mathrm{mL} \text { Sample } \\
\text { matrix effects } \%\end{array}$ & $\begin{array}{c}1 \mathrm{ng} / \mathrm{mL} \text { Sample } \\
\text { matrix effects } \%\end{array}$ & $\begin{array}{c}10 \mathrm{ng} / \mathrm{mL} \text { Sample } \\
\text { matrix effects } \%\end{array}$ \\
\hline JWH-122 & 99.3 & 94.6 & 97.8 \\
5F-AMB & 104.2 & 106.1 & 97.7 \\
AMB-FUBINACA & 91.4 & 95.8 & 90.7 \\
UR-144 & 97.9 & 98.9 & 92.9 \\
RCS-4 & 83.6 & 91.9 & 101.8 \\
AB-CHMINACA & 89.8 & 93.8 & 95.3 \\
AB-PINACA & 76.7 & 96.8 & 94.0 \\
MDMB-FUBINACA & 98.0 & 81.6 & 92.6 \\
5F-ADB & 92.5 & 91.9 & 98.1 \\
ADB-FUBINACA & 94.0 & 97.0 & 101.2 \\
5F-MDMB-PICA & 105.2 & 92.0 & 97.9 \\
\hline
\end{tabular}

Table 3 Synthetic cannabinoids matrix effects in urine matrix

\begin{tabular}{ccccccc}
\hline \multirow{2}{*}{ Compound } & \multicolumn{2}{c}{$1 \mathrm{ng} / \mathrm{mL}$} & \multicolumn{2}{c}{$10 \mathrm{ng} / \mathrm{mL}$} & \multicolumn{2}{c}{$100 \mathrm{ng} / \mathrm{mL}$} \\
& Recovery \% & RSD\% & Recovery \% & RSD\% & Recovery \% & RSD\% \\
\hline JWH-122 & 78.85 & 2.14 & 75.04 & 0.52 & 79.63 & 0.85 \\
5F-AMB & 76.03 & 18.68 & 75.84 & 0.92 & 95.85 & 0.59 \\
AMB-FUBINACA & 107.70 & 18.95 & 79.26 & 3.62 & 71.03 & 2.21 \\
UR-144 & 75.58 & 16.51 & 72.08 & 7.39 & 81.99 & 12.59 \\
RCS-4 & 85.94 & 9.77 & 78.78 & 5.31 & 76.26 & 7.89 \\
AB-CHMINACA & 93.76 & 11.43 & 87.90 & 15.67 & 98.82 & 10.16 \\
AB-PINACA & 118.39 & 9.98 & 69.90 & 4.38 & 82.00 & 7.29 \\
MDMB-FUBINACA & 73.07 & 3.97 & 76.04 & 6.62 & 91.38 & 6.03 \\
5F-ADB & 94.59 & 10.25 & 74.59 & 3.30 & 92.04 & 7.02 \\
ADB-FUBINACA & 106.17 & 8.95 & 72.3 & 8.95 & 100.49 & 13.26 \\
5F-MDMB-PICA & 82.75 & 10.22 & 70.38 & 6.32 & 74.61 & 5.44 \\
\hline
\end{tabular}

Table 4 Spiked recoveries for 11 synthetic cannabinoid urine samples 
Figure 1 Chromatography-mass spectrometry of standard solution $(10 \mathrm{ng} / \mathrm{mL})$

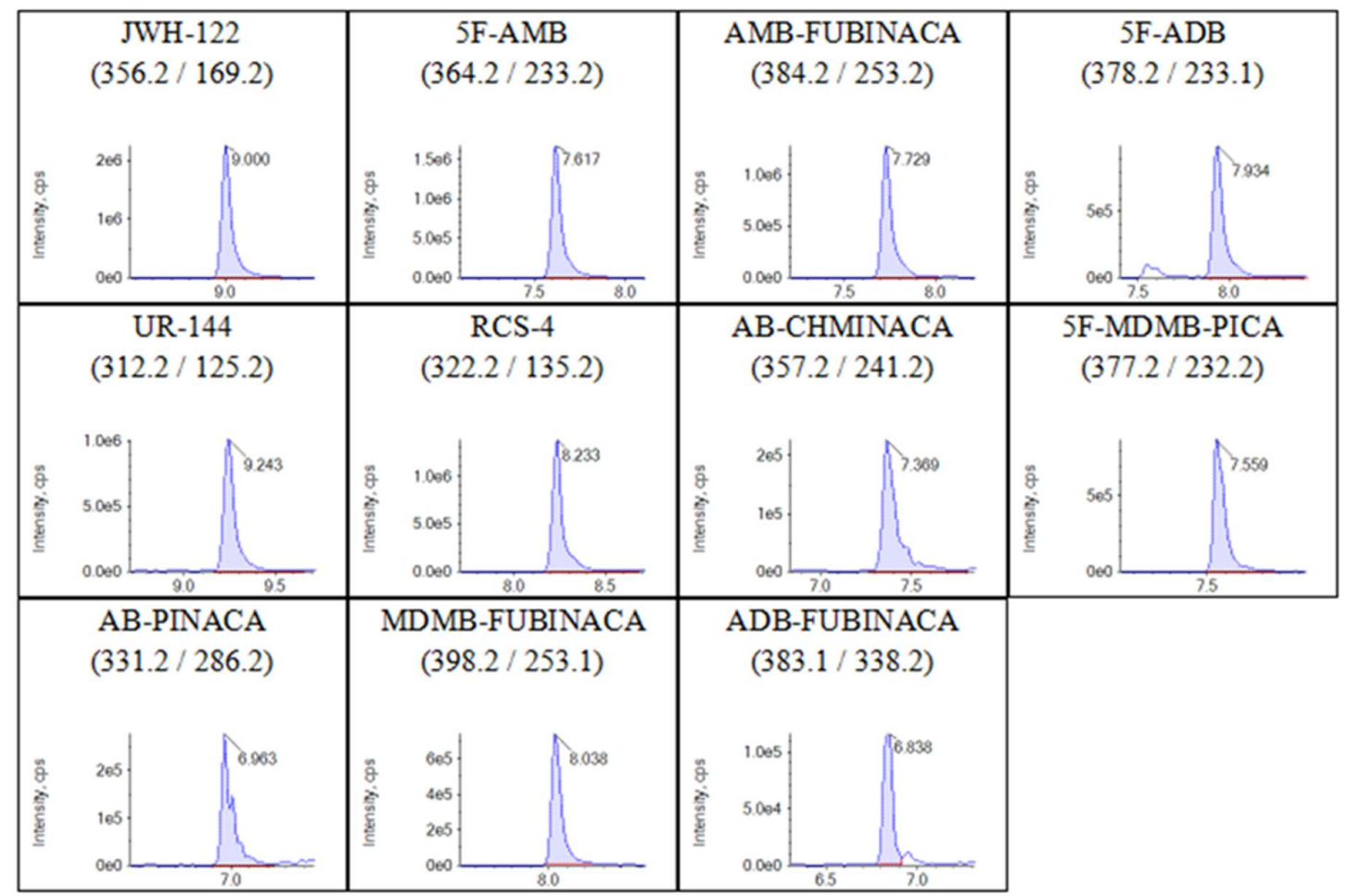

Figure 2 Optimization of acetonitrile volume in solid phase extraction

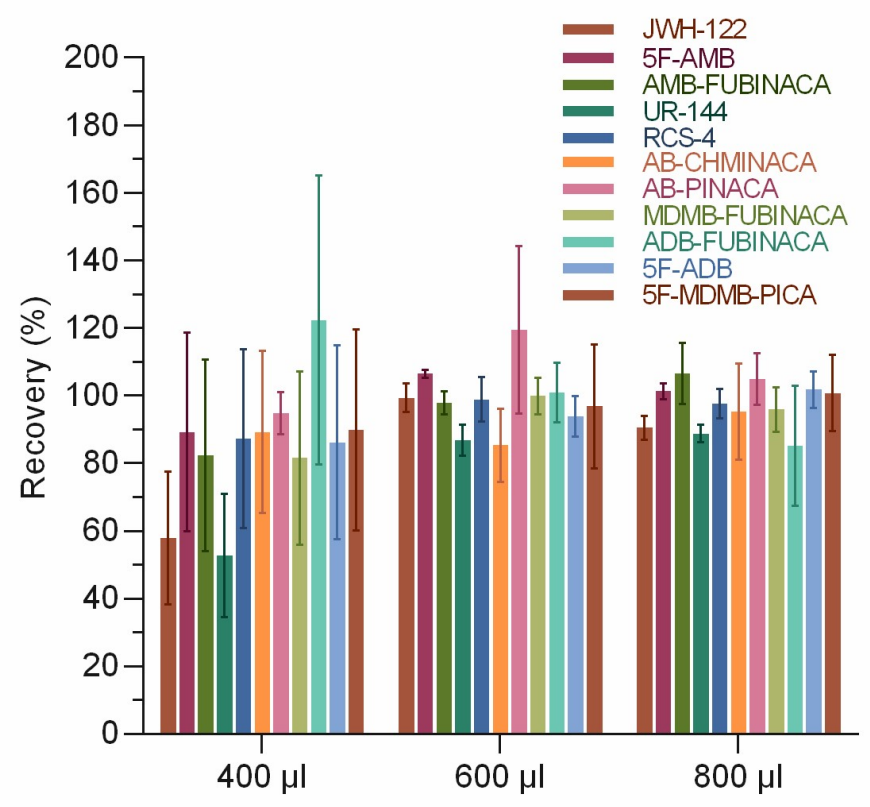


Figure 3 Effect of elution reagent volume on extraction recovery

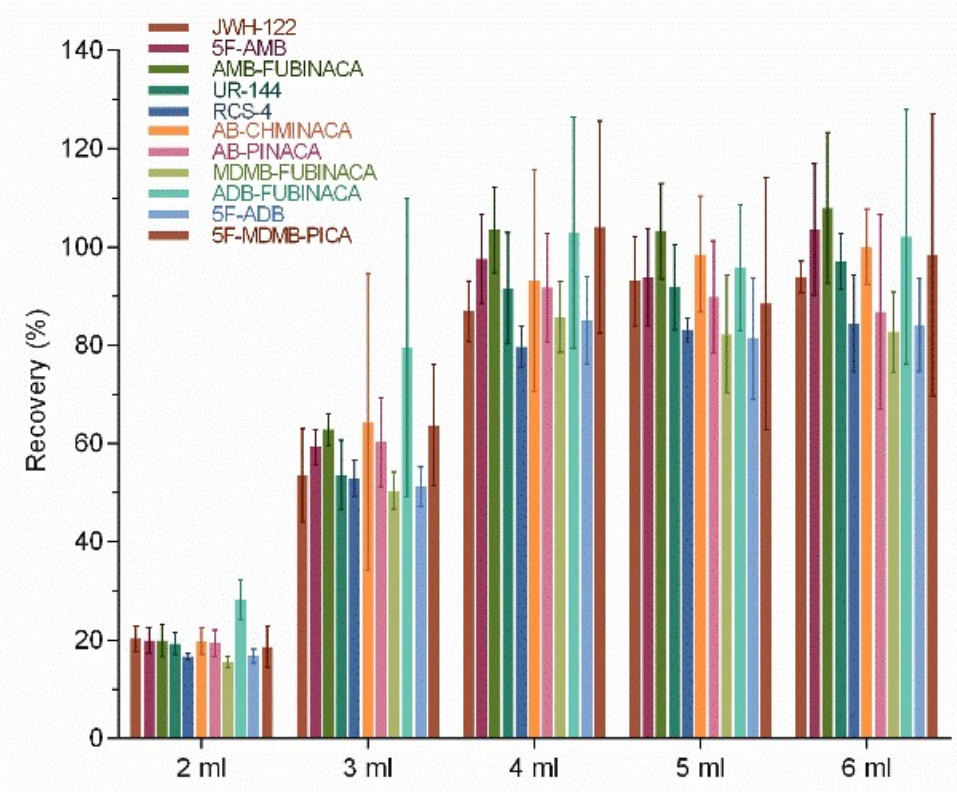

